\title{
The wine consumer's behaviour in selected stores of Italian major retailing chains
}

\author{
Chiara Seghieri, Leonardo Casini and Francesco Torrisi \\ Department of Agricultural Economics and Land Resources, \\ University of Florence, Italy
}

\begin{abstract}
Purpose - The principal aim of this article is to examine attitudes of Italian consumers in relation to wine, identifying specific types of wine buyers.

Design/methodology/approach - A sample of 442 Italian wine consumers has been surveyed and three measurement instruments have been developed for grouping the observations by means of multivariate statistical analysis. The study then investigates both the consumer and product characteristics that significantly differentiate between the derived clusters of buyers and finally provides an external validity check.

Findings - Although the study is exploratory in nature, there is evidence that four wine-related consumer segments exist in our sample. These segments are habitual wine buyers, rational buyers, interested consumers, and professionals of promotions.

Originality/value - For wine marketers, the results of this research clearly support the need for a targeted approach to their consumer market. The study identifies the principal consequences of the results in order to provide both retailers and producers some useful marketing suggestions.
\end{abstract}

Keywords Wines, Market segmentation, Consumer research, Italy

Paper type Research paper

\section{Introduction}

The world wine market

In more recent years, the world wine sector has developed substantially, leading to a significant change in the structure of the wine market. On the demand side, for instance, some major features have been reduced consumption per capita in traditional wineproducing countries (i.e. France, Italy, Spain), and increased consumption of wine in a few countries which are not traditionally wine-producing, such as the USA. Furthermore, on the supply side there are now signs that world productive capacity is increasing faster than the rate of world consumption. In this context, the world wine market can be characterized by an ever-increasing competition, fueled on one side by the increasing production, and on the other side by changing consumption patterns. In addition, changing consumer lifestyles have made significant impacts on overall wine sales.

Specifically, in Europe, wine producers face declining domestic wine consumption per capita, increasing concentration in distribution, increasing imports from third (world?) countries and other stable exports, and hence increased overall price pressures. Besides changes in consumption per capita, there has been long term downward trend in both European Union (EU) production and consumption of table wine and an increase in both production and consumption of quality wine: it seems that wine is now drunk on fewer occasions, but with a greater demand for quality wines.

\section{The Italian wine consumers}

Among the EU wine producers, Italy, in particular, has been deeply affected by the dramatic changes in the wine market. The last few years have been marked principally
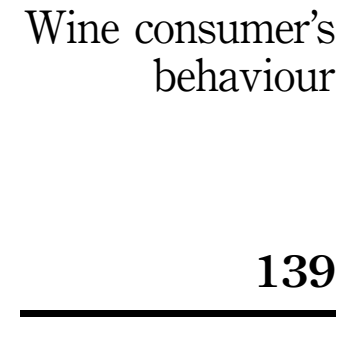
IJWBR

19,2

140 by a long period of decreasing wine consumption. Conversely, although Italy is leading Europe with the highest amount of wine producers, the production in this country has declined as well. The average consumer is also changing with the decrease in consumed and purchased volume of wine: he now tends to buy higher priced and higher quality wine products than in recent years.

It is, in fact, worth highlighting the steady decline in production, as well as in hectares of vineyards, in contrast to a clear improvement in quality. DOC/DOCG wine production in all the Italian regions has significantly increased, although this index does not strictly refer to quality. Domestic DOC/DOCG wine production grew from 1/7 to $1 / 3$ of the total wine production in the past few years.

In the commercial area, also, the purchase of DOC/DOCG wines recorded a steady growth in the past decade. This was countered by a decline in the consumption of lower quality table wines, falling from 30 million hectolitres in the early 1990s to approximately 20 million hectolitres at the present time. This trend resulted in a general decline in wine consumption, which fell to 29 million hectolitres, as compared to more than 35 million hectolitres ten years ago.

All these changes in the Italian market are mostly the consequence of a deep change in lifestyle, in the traditional food habits and in a number of cultural and taste factors. For many years, wine has played a large role in everyday culture for Italians, who used to drink their habitual wine everyday, especially at home during both principal meals. New consumption styles are currently emerging, mainly linked to different dispositions, interests, and needs for the product. On the one hand there is the traditional consumer, still the main consumer, who always drinks the same known varieties of wine during meals, without paying particular attention to the wine cues such as the origin or certification. On the other hand, there is a new generation of consumers who are more aware of what they are drinking, specifically regarding taste and quality. These new consumers, estimated at around 6 million, are usually young professionals of medium to high income, who often consider themselves wine experts and prefer drinking premium wines, mainly in a social context.

As the 40th edition of Vinitaly, the leading wine event in the world (scheduled 6-10 April 2006), suggests: "Classic targets may be on the wane; wine is now mostly consumed at dinner rather than at lunches. Since today's market increasingly focuses on 'tribes'. New life styles no longer associate wine with meals but also and especially enjoy it in social settings. This "revolution" especially concerns young people (university students in particular are very attentive consumers) and women, who now enjoy total independence when selecting bottles. Major growth involves young people82 per cent favour wine - and women - 32 per cent enjoy a bottle of wine with friends; older people - for income, health and life style reasons - are becoming less frequent consumers: older people buying wine are apparently down by more than 25 per cent" (Press release - Verona Fiere Press Office, in collaboration with WineNews).

Finally, the wine market is also changing from the point of the distribution channels, where 55 per cent of the still and sparkling wines consumed in Italy are now bought in the main modern distribution formats, i.e. supermarkets and hypermarkets. The traditional food outlets and wine shops rank second, with a 17 per cent share.

\section{Research objective}

Given that wine is becoming seen increasingly as a lifestyle beverage and a more acceptable and desired product, more and more wineries are recognizing the need to launch new products and brands, to target existing and new markets more specifically, 
and to better address the needs and wants of actual and potential wine buyers. As a consequence, marketers should consider how they can and do achieve impact on the various consumer profiles, especially throughout the entire purchase decision process, from the initial information search phase until the final product choice.

In this context, the main objective of the present study is to provide an attempt to analyze a sample of wine consumers in order to detect the different characteristics of both the "traditional" and "new" wine buyers in selected stores of the Italian modern distribution. Moreover, the research was designed to explore how the defined profiles behave during the decision-making process in the wine department; in particular, the varying degrees of importance given to product cues and product information by consumers during the purchasing process.

\section{Methodological framework}

In the field of marketing research, researchers have often relied on intuition and sociodemographic information such as age, income level and occupation for identifying different consumer profiles. However, in the last few years within the general marketing literature, there has been a growing body of research showing that consumers do not respond during the purchase process in a predictable, uniform manner to the marketing strategies. Research also shows that the impression those marketing strategies have on the individual depends on a number of other variables besides his socio-demographic characteristics, such as his level of involvement, subjective knowledge, usage experience, and general disposition towards the product category. As a consequence, utilization of qualitative data to study the consumers' attitudes is currently becoming more prevalent, especially in USA and Australia, where researchers often invoke a new, multidimensional concept as the construct of "involvement" to measure the different levels of individual's disposition towards the product (Laurent and Kapferer, 1985; Mittal and Lee, 1989; Slama and Tashchian, 1985; Lockshin et al., 1997).

More in-depth, the concept of involvement is widely spread and used as a segmentation variable in consumer behaviour literature. The definition of this concept has varied since the early days of Sherif and Cantril (1947). Rothschild (1984), for instance, defined involvement as a motivational and goal directed emotional state that determines the personal relevance of a purchase decision to a buyer. Earlier researches extended the concept of involvement to a multidimensional concept, allowing literature to develop several types of measures, including those related to product, brand, purchase, and advertising involvement (see Andrews et al., 1990; Mittal and Lee, 1989, for a recent review). Moreover, a substantial body of empirical literature (Zaichkowsky, 1985; Laurent and Kapferer, 1986; Valette, 1989; Goldsmith et al., 1991) has been dedicated to developing and validating instruments specifically designed to indirectly measure this latent concept. In general, Bearden et al. (1999) recommend using only multi-item measures, independent from the final measure adopted. However, practice shows that robust results can also be obtained with a reduced number of items (Mittal, 1995). In this context, the product involvement scale has been obtained on the basis of items taken from already developed and tested scales such as those in the study of Mittal (1989) and Lockshin (1997).

In constrast to the abundance of material published in other countires, to our knowledge only a small body of literature has been produced in Italy regarding the analysis and segmentation of Italian wine consumers based on their attitudes toward

\section{Wine consumer's behaviour}


IJWBR

19,2

142 the product category (i.e. Marangon and Troiano, 2004; Berni et al., 2005; De Luca and Vianelli, 2003).

This having been said, in this study the data from a questionnaire on Italian wine consumers' behaviour has been analyzed by means of a cluster analysis in order to identify wine buyers' profiles. Specifically, the clusters have been determined on the basis of three measures. These measures are related to different aspects of the consumer-product relationship (i.e. the consumer's involvement in wine, his price sensitivity) and are detected by applying a factor analysis to the data gained from the questionnaire. Subsequently, by focusing on the purchase decision-making process, the characteristics of the product (i.e. brand, price, country of origin), that consumers use as evaluative criteria in the buying process can be determined. This information can then be used to better differentiate and confirm the cluster profiles. On the basis of these results, the authors can provide both retailers and producers with specific communication advice, possibly leading to the substantiation and development of an effective marketing campaign.

\section{The direct survey}

The Department of Agricultural Economics and Land Resources performed an explorative, consumer-based market survey in 14 points of sale, representative of seven banners (hypermarkets and supermarkets) and three Italian regions (Lombardy, Tuscany, and Lazio). The sampling plan was based on the three regions, and of these concentration was placed primarily on Tuscany. Tuscany is, in fact, one of the main Italian wine producing regions, while Lazio and Lombardy are representative samples of southern and northern regions, respectively. The stores were initially planned to be selected thorough a somewhat random sampling based on characteristics such as geographic position (inside and outside urban centres), and store size, among others. However, due to the refusal of some of the selected stores to let the researchers conduct interviews, the sample has been chosen in order to reduce bias.

The final sample consisted of 442 wine consumers, interviewed immediately after their purchase in the wine shelf space. This was done in order to capture their perceptions and behaviours concerning the product they bought, and their general attitudes towards the whole wine market as accurately as possible.

Table I shows the distribution of the basic socio-demographic characteristics of the respondents. Out of the 400 respondents who completed the questionnaires, 63 per cent were male and 37 per cent were female. Most of the wine buyers were 30-49 years old, were married and tended to live in families of three components, and were born in the centre of Italy. Moreover, a large percentage of the whole sample (80 per cent) had a high educational level, and only 11 per cent of the respondents reported that they were in bad economic condition.

\section{The questionnaire}

The questionnaire has been divided into five parts[1]. The first part concerns the main characteristics (i.e. price, colour, brand and so on) of the wine purchased directly prior to the interview. The second part describes information on the consumers' behaviour in the wine department. In particular, their purchase intentions, the kind of information read on the wine shelf and/or label, and their final reasons for purchase. The frequency of wine consumption and purchase by consumers is contained in the third part, while the fourth part deals with the consumers' satisfaction with the store, and, in particular, with the organization of the wine department. The last part of the questionnaire, in 


\begin{tabular}{|c|c|c|}
\hline Variables & Percentage & Wine consumer's \\
\hline \multicolumn{3}{|l|}{ Gender } \\
\hline Male & 63.1 & \\
\hline Female & 36.9 & \\
\hline \multicolumn{3}{|l|}{ Age } \\
\hline $16-29$ & 9.6 & 14 \\
\hline $30-49$ & 53.8 & 14 \\
\hline $50-64$ & 26.8 & \\
\hline $65+$ & 9.9 & \\
\hline Married & 78.5 & \\
\hline \multicolumn{3}{|l|}{ Residence } \\
\hline North Italy & 18.8 & \\
\hline Centre Italy & 43.3 & \\
\hline South Italy & 35.0 & \\
\hline Europe & 2.9 & \\
\hline High education & 75.5 & \\
\hline \multicolumn{3}{|c|}{ Subjective well-being } \\
\hline Low & 11.5 & \\
\hline Medium & 40.3 & \\
\hline High & 48.2 & \\
\hline \multicolumn{3}{|c|}{ Household dimension } \\
\hline 1 & 9.3 & Table I. \\
\hline 2 & 27.6 & Sample of socio- \\
\hline 3 & 32.1 & demographic \\
\hline $4+$ & 31.0 & characteristics \\
\hline
\end{tabular}

addition to collecting the respondents' socio-demographic characteristics, includes the consumer's responses to nine questions. These questions are expressed in the form of 4-point Likert scale, which yields a set of information on the consumer - product relationship such as the consumer's level of expertise in the wine field, and his sensitivity towards promotions.

\section{The factor analysis}

The nine items mentioned above, regarding the consumer - product relationship were submitted to factor analysis with varimax rotation[2]:

(1) How would you define yourself concerning wine?

(2) I like to have wine that match with the food I am going to eat

(3) I always buy the wines I know and I have already tasted

(4) When I buy wine I am sensitive to promotion appeals

(5) I am willing to spend a great amount of money to buy a high quality wine

(6) I always buy the same wine, that one I am used to drink at meals

(7) I buy wine thinking about the different tastes of whom is going to drink it

(8) I taste new wines if they under promotion

(9) I often like drinking new kind of wines. 
IJWBR

19,2

144
The factor analysis was used to undertake two operations: to reveal the existence of the possible underlying structures within the data, and to ascertain whether the resultant scales represented types of measurements related to different aspects of the consumerproduct relationship.

As we would expect, the extraction process shows that three factors may be retained in the analysis (eigenvalues $>1$ ), which account for about 60 per cent of the total inertia of the data set. Two items with relatively high cross-loadings $(>0.4)$ were removed from the scales. The three scales obtained, including the deleted items, and the factor loadings are shown in Table II. Finally, internal scale validity was verified using the Cronbach alpha index and all three scales reported quite high values (alpha around 0.65). Therefore, the first scale was labelled "product involvement"; in this context, the scale obtained is a combination of items which have been already tested and used in literature to measure the concept of product involvement (see for instance: Mittal and Lee, 1989; Lockshin, 1997). The other two scales involve factors concerning the tendency to drink habitually wines at meals, and the tendency to purchase during promotion; consequently, they were labelled "habits sensitivity" scale and "price sensitivity scale", respectively. In the authors' opinion, these two latter scales can be considered as other purchasing involvement facets, as suggested by Laurent and Kapferer (1985) and Mittal and Lee (1989). However, the authors prefer to address them in a different way. In fact since, for the potential of involvement, and all the latent concepts in general to be realised, they usually needs to be submitted to more stringent and rigorous theoretical and empirical examination which, unfortunately, could not have be undertaken in this context, due to the nature of the questionnaire.

From the factor analysis, all the three measures appear to be measured efficiently and thus the obtained factors can be considered sufficient to be used in subsequent analysis. Consequently, factor scores (i.e. the values that the latent variables would have received if they had been directly observable) for each construct were calculated using the regression approach and were then saved for the second part of the study.

\section{The cluster analysis}

The second methodological part of the present research consists of an attempt to cluster-analyze the sample using the above detected three constructs (product involvement, habits and price sensitivity scales). In the wine marketing context different aspects of the consumer-product relationship, such as brand, product, and purchasing involvement, together with socio-demographics and usage behaviour, have

\begin{tabular}{lccc}
\hline Variable & Product involvement & Habits sensitivity & Price sensitivity \\
\hline Interest toward wine & 0.65 & -0.13 & -0.18 \\
Food matching & 0.68 & 0.19 & 0.03 \\
Already tasted wines & 0.16 & 0.78 & -0.16 \\
Sensitive to promotion appeals & 0.11 & -0.16 & 0.78 \\
High willingness to pay & 0.74 & 0.00 & 0.18 \\
Habitual wine at meals & -0.12 & 0.82 & 0.04 \\
Drinkers' tastes & 0.50 & 0.12 & 0.46 \\
Taste new wine if it is in promotion & -0.02 & 0.05 & 0.84 \\
Like drinking new wines & 0.54 & -0.29 & 0.52 \\
Eigen-value & 2.60 & 1.60 & 1.24
\end{tabular}

Table II.

Rotated factor pattern 
been used extensively as tools to detect different segments of wine consumers (i.e. Lockshin, 1997, 2002; D'Hauteville, 2003).

As recommended by Singh (1990), factor scores rather than the raw data are used for the three scales, because raw data contain interdependencies that are likely to bias the cluster solution. The $K$-means cluster analysis on the basis of Euclidean distances (Anderberg, 1973) has been performed and three-, four-, five-, and six-cluster solutions were determined; however the four-cluster solution worked the best based on the pseudo $F$-statistic (Calinski and Harasbasz, 1974).

Before going further, the stability of the four-cluster solution was examined using the cross-validation procedure recommended by Punj and Stewart (1983). In other words, the data were split into two random sets, a cluster analysis was performed on the first set, and the cluster centroids. The centroids were then used to classify the observations of the second set using Euclidean distances. Finally, the data from this last experiment were tested for correlation with a cluster analysis performed on the second set using Cronbach alpha. Agreement was found in about 80 per cent of the cases. The mean values of the three scales assumed by the four clusters are described in Table III.

The clusters were then labelled as follows:

(1) The first cluster, the usual buyers, was made up of individuals positive on the habits sensitivity scale and negative on product involvement and price sensitivity. Individuals in this cluster did not respond to price oriented appeals, and were not particularly involved in the wine category.

(2) The second cluster, the rational buyers, is positive on all the three scales, but slightly lower on the habits orientation. They indicated that they were somehow interested in the product, probably would like to try new varieties of wine, but they are also price sensitive and only take risks trying a new wine during a promotion. This type of profile is common among Italian wine consumers in general. The average Italian wine consumer is usually interested in wine, spends time in front of the wine shelf looking for good wines, and tries to buy the best quality wine at the lowest price that he can find.

(3) The third group, the professionals of promotions, are those respondents who respond readily to the promotional activities in supermarkets, do not seem interested in wine, and do not drink wine habitually with meals. These types of consumers score high on the price orientation scale and negative on the other two scales.

(4) Finally, the fourth group of consumers, interested consumers, are positive on the product involvement and negative on the other two measures. They are involved in the product, enjoy looking for new kinds of wine to taste, and are willing to pay more for high quality wines. Differences across the four clusters

\begin{tabular}{lcccc}
\hline $\begin{array}{l}\text { Cluster } \\
\text { number }\end{array}$ & $\begin{array}{c}\text { Product } \\
\text { involvement }\end{array}$ & $\begin{array}{c}\text { Habits } \\
\text { sensitivity }\end{array}$ & $\begin{array}{c}\text { Price } \\
\text { sensitivity }\end{array}$ & $\begin{array}{c}\text { Number of } \\
\text { observations }\end{array}$ \\
\hline 1 & -0.80 & 1.19 & -1.18 & 58 \\
2 & 0.76 & 0.38 & 0.72 & 111 \\
3 & -0.72 & -0.54 & 0.41 & 123 \\
4 & 0.74 & -0.64 & -0.90 & 67
\end{tabular}

Table III. The cluster means 
IJWBR

19,2

146 were then further analysed in relation to the socio-demographics variables and to the consumption-purchase frequency information.

Age and sex appeared to differ across clusters: males were likely to be more product involved than females, while the usual buyers category has the highest number of elderly drinkers $(F=14.3, p<0.05)$. On the other hand, females neither habitually drink wine at meals, nor are they interested in wine aesthetically, and they seem to purchase wine only in case of promotional appeals $\left(\chi^{2}=22.5, p<0.05\right)$. Perceived well being also differs significantly across the segments $\left(\chi^{2}=8.9, p<0.05\right)$, with the interested consumers followed by the rational consumers having the highest levels, while the professionals of promotions and the usual buyers the lowest. Lockshin et al. (1997) found income a significant variable in differentiating among different wine consumer profiles. According to this study, consumers who are not very interested in wine, the so called uninvolved shoppers, have the lowest income level. The same result was also found later by D'Hauteville (2003) who also demonstrated how other demographics such age and sex differed significantly among consumer profiles.

Finally, the interested consumers have the highest consumption frequency levels, followed by the usual buyers and the rational consumers. The majority seem to drink wine almost every day and to purchase it at least once a week; on the other hand, the professionals of promotion do not consume wine as often $\left(\chi^{2}=8.2, p<0.05\right)$. The rational buyers purchase wine at least once a week, followed by the interested and the usual buyers; this was usually in quantities of seven bottles or more. As in consumption frequency, the professionals of promotion are the lowest in the purchase frequency as well $\left(\chi^{2}=27, p<0.05\right)$. The frequency of visits to the wine shelf also appear to differ significantly across the four groups, with the interested consumers the highest (they visit the wine department every time they enter the market) and the professionals of promotion the lowest $\left(\chi^{2}=21.6, p<0.05\right)$.

Let us now turn our attention to the relationship between the clusters of consumers and their purchase-making process once in the wine department of a store. A considerable amount of research is, in fact, dedicated to examining the different strategies that consumers use to make purchase decisions. Although it is usually difficult to navigate the complexities of the consumer decision-making process, it is evident that there are number of factors involved, both from the consumer and the product side. These factors are involved in all the phases of the process and are open to analysis. Consequently, acquiring knowledge of the greatest precision possible of the overall process is an issue of particular scientific interest. In particular, the wine market deserves special consideration because consumer choice regarding wine is more complex than the choice of many other products. Wine consumers, for example, are exposed to a vast array of various product attributes when making a purchase decision, due to the nature of the wine. The characteristics of wine vary with vintage year, producer, region, and production technique, among other factors. In addition, within the wine marketing literature, researchers have found a significant relationship between the consumer disposition towards the product and the purchasing process. For instance, consumer's involvement in the wine category has been found to impact the way the buyer makes purchase decisions, and how he uses wine attributes as evaluative criteria in the product selection process. Lockshin et al. (2001) demonstrated that an individual who is highly involved in the wine industry is likely to spend time considering consumption situations; moreover, he enjoys learning about wine and generally takes a more "cognitive" approach to wine cues. 
In the present study, purchase behaviour is indeed found to significantly differ across the clusters with respect to the consumer's use of wine cues as evaluative criteria. Furthermore, before entering the store, the usual buyers do not seem to be predisposed to try new products, to switch brands, or to seek out more information about unfamiliar wines. In fact, they may have already planned to buy a particular kind of wine with certain characteristics, the first of which is usually the region of origin $\left(\chi^{2}=12.5, p<0.05\right)$. Conversely, the professionals of promotion are the least likely to have a predetermined wine choice. Once in front of the wine shelf, the importance given to the different factors driving the consumers towards wines differed significantly across the segments. The interested buyers, for example, were the highest declaring that they first searched for information regarding the wine varietals (such as Chianti, Lambrusco, and so on) $\left(\chi^{2}=6.9, p<0.05\right)$. The traditionalist consumer, on the other hand, starts distinguishing different kinds of wine based on of the product's shelf position, and is followed in this characteristic by the rational consumer $\left(\chi^{2}=6.8\right.$, $p<0.05)$. As expected, the professionals of promotion give high importance to the price information, while, in contrast, the interested consumers seem to be indifferent to this characteristic $\left(\chi^{2}=12.8, p<0.05\right)$.

Having identified the product choices positioned on the wine shelf, the reason driving the consumers' final choice, again, is found to differ significantly across the clusters. The professionals of promotion were the highest to choose primarily on the basis of the product price, while the interested buyers were the lowest, followed by the usual buyers $\left(\chi^{2}=13.9, p<0.05\right)$. The usual buyers have, in fact, the highest percentage of consumers making their final product choice on the basis of product experience (they prefer to choose among familiar wines) $\left(\chi^{2}=22.9, p<0.05\right)$. On the other hand, the interested buyers are the most likely to make a wine choice based on selected wine attributes, such as colour and brand $\left(\chi^{2}=9.9, p<0.05\right)$. The price paid by consumers for the wine bought immediately prior to the interviews differed significantly across the segments[3]. The interested individuals spent the most (mean price around seven euros), followed by the rational consumers and the usual buyers, with the professionals of promotions spending the least (mean price around three euros). All these results seem to be in accordance with previous research, which show the difficulty of predicting the evaluative criteria of consumers, due to individual differences. However, among a multitude of criteria, both the product cues (such as brand, label and price), and the product experience are the principal evaluative criteria used by consumers during the buying process (Halstead, 2002; Spawton, 1991). Table IV provides a summary of the four profiles.

\section{Final remarks and conclusion}

The findings of this study suggest that a wide range of factors influence the consumers' purchase process. With regard to the wine industry, consumers usually face various competitive products, and thus are more likely to take time to evaluate product alternatives in terms of brand, colour, price, and country-of-origin. However, how and why the consumers make the final product choice changes according to different individual relationships within product categories. As such, we believe there is a need for effective marketing strategies. We must first classify our sample of consumers on the basis of their attitudes towards wine, and then analyze the importance given to the product cues during the purchase decision process, in addition to demographic and usage variables. This two-fold analysis allowed us to detect four distinct consumer profiles, each of them with different product attachments, different 
IJWBR

19,2

148

Table IV.

The four clusters
Cluster 1: The usual buyers

Sensitive to fixed habits, no product involvement, no price sensitivity. Around 60 years old, low level of well being. High consumption/purchase level. Consume wine every day, with meals, and purchase it at least once a week. Low level of differentiation in wine category, they usually drink known, already tasted wines. They planned their product choice before entering the market, thus their purchase decision is limited by a habitual decision-making process that involves little cognitive effort.They do not spend time exploring new alternatives, and make their final choice among habitually preferred wines.

Cluster 3: The professionals of promotion Sensitive to promotional appeals, no product involvement, no habits sensitivity. Usually females, the youngest among the groups, declaring the lowest level of subjective wellbeing.Lowest in consumption and purchase frequency.They prefer to buy wine if there are promotional activities. They evaluate among different alternatives only on the basis of the price information displayed on the shelf.

\begin{abstract}
Cluster 2: The rational consumers
Positive on all three scales but very low habits sensitivity.High level of subjective well being. Mean age is 43 years.Consumption level moderate, high frequency of purchase.Before entering the store, they do not have a predetermined choice of wine.After the usual buyers they are the second highest searching for product which has a consistent position on the shelf.At the same time, they are affected, together with the professionals of promotions, by product price during their decision-making process. They state an interest in product category but they try to get the best quality/ price ratio from their product choice.
\end{abstract}

\section{Cluster 4: The interested buyers}

Positive only on product involvement.Usually male, mean age around 45 years old, highest level of well being.High level of purchase and consumption frequency.They read information regarding the different varieties of wine displayed on the shelf. They do not care about the price information. Respond to wine cues such as colour during the final phase of the purchase decision-making process.

uses of evaluative criteria during the product choice, and distinct consumption and purchase patterns.

All these elements, particularly the different levels of consumer-product relationship characterizing the consumer profiles could be used by both retailers and producers to design more effective marketing strategies. In addition, since products are more manipulated during experiments than consumers, companies might approach the consumer-product relationship from the product point of view in order to obtain better results. For example, retailers might organize the shelf space in the way to combine the best position for each product according with the related target segment. In general, wine consumers are characterized by a low rate of predetermination and a majority of the purchase decision process is taken in front of the offer, in the wine department of a store. As a consequence, how the shelf space is organized to attract the consumer's attention is a very important consideration. For example, the wine department could be organized by means of wooden and personalized shelves, in order to look more like a shop than a supermarket. The goal would be a final layout aimed to give a higher level of elegance to the wine department, and especially to attract the attention of the involved buyer category.

On the basis of the results of our analysis, we also suggest that retailers take into account how differently the consumer types behave during their choice process, and then to organize the wine department accordingly. For instance, we see that the usual buyers are used to planning their product purchase before getting into the store and, consequently, spend less time in front of the shelf. We believe this consumer type does 
not need a target position on the shelf for his preferred wine; this kind of consumer should be able to find the product easily just by looking for distinctive packaging.

The same approach is shared with the professionals of promotion, but with a different purpose: they usually look for the product with the lowest price. In fact, they do not care about packaging or shelf organization, and retailers could thus easily serve their needs by reserving a place exclusively for promotional appeals.

Conversely, the interested consumers do not care about the product price and could be targeted through an effective organization of the wine shelf. Retailers might reserve well-organized shelf space for Ultra-premium and Icon wines. This kind of consumer spends a lot of time in front of the shelf and his choice is usually focused on specific top products.

Finally the rational consumer is used to buying wine frequently and in greater quantities. He also spends a lot of time in front of the shelf, since he is intending to find the best wine in terms of price/quality ratio. Consequently, he needs to have a broad selection placed before him in order to make an optimal choice among all the products available. His attention, like that of the interested consumer, could be attracted by a captivating label and other aesthetic devices, such as the design of the bottle. His decision process could also be helped with visual devices explaining principal wine characteristics and possible combinations with dishes/recipes. These two last groups of consumers, typically well-educated, are less exposed to traditional advertising such as television, radio, and popular magazines, and could be reached with a publicity campaign involving news releases and travel, food/cooking, and lifestyle magazines.

Finally, producers might also analyze the profiles of the different clusters in order to target the segment with the highest consumer potential. Effective, suitable strategies are indeed request such as labels with different complexity according to the reference target, for example an essential label for the usual buyer, a detailed one for the interested and a creative label for the rational consumer.

No less important are price policies, which should take into account that certain kinds of consumers are driven only by promotions, while others consider the price as the principle quality indicator. The majority, however, is interested in finding the wine they would like at the price they expect.

Although we have provided the managers with useful advice and the sample was surveyed on different days and at different times, one major limitation of the study is the nature of collection method (interviews in supermarkets) that limits our ability to generalise our results. Moreover, the two measures related to price and habits sensitivity would need deeper construct validity, such as focus groups with specialists and expert judgement in the item selections.

As a consequence, further research (such as performing more detailed and representative surveys and implementing other statistical tools) is needed in order to better examine the relationship between the different types of wine consumers and the factors of their purchase decision process.

\section{Notes}

1. Due to space limitation all the items of the questionnaire are not described in detail. The questionnaire can be obtained from the authors, on request.

2. The nine items are expressed in form of 4-point likert scale from disagree to agree, except that one related to product interest (item number one) which ranges from I do not like wine to I am a wine expert.

Wine consumer's behaviour 
IJWBR

19,2
3. We decided to consider the price paid by the consumers for the wine bought during the interview occasion even though it is not representative of the average price paid for every day consumption.

\section{References}

Anderberg, M.R. (1973), Cluster Analysis for Applications, Academic Press, New York, NY.

Andrews, J.C., Durvasula, S. and Akhter, S.H. (1990), "A framework for conceptualising and measuring the involvement construct in advertising research", Journal of Advertising Research, Vol. 19 No. 4, pp. 27-40.

Bearden, W.O., Netemeyer, R.G. and Mobley, M.F. (1999), Handbook of Marketing Scales: Multi Item Measures for Marketing and Consumer Behavior Research, 2nd ed., Sage, Newbury Park, CA.

Berni, P., Begalli, D. and Capitello, R. (2005), "An occasion-based segmentation approach to the wine market in Denmark", Journal of International Food and Agribusiness Marketing, Vol. 1, pp. 117-45.

Calinski, T. and Harabasz, J. (1974), “A dendrite method for cluster analysis”, Communications in Statistics, Vol. 3, pp. 1-27.

D'Hauteville, F. (2003), "The mediating role of involvement and values on wine consumption frequency in France", Proceedings of the Wine Marketing Colloquium, Adelaide, July.

De Luca, P. and Vianelli, D. (2003), "Coinvolgimento del consumatore e valutazione dell'atmosfera del punto vendita", in Collesei, U. and Andreani, J.C. (a cura di), Atti del Terzo Congressso Internazionale sulle Tendenze di Marketing - Ca' Foscari, Venezia 28-29 novembre 2003, Venezia.

Goldsmith, R., Emmert, J. and Hofacker, C. (1991), "A causal model of consumer involvement: replication and extension", AMA Winter Educators Conference, Chicago, IL.

Halstead, L. (2002), "How do consumers select wine? Factors that affect the purchase decision making process in the wine category", Annual Academy of Marketing, Nottingham.

Laurent, G. and Kapferer, J. (1985), "Measuring consumer involvement profiles", Journal of Marketing Research, Vol. 22, pp. 1-53.

Lockshin, L., Quester, P. and Spawton, T. (2001), "Segmentation by involvement or nationality for global retailing: a cross-national comparative study of wine shopping behaviours", Journal of Wine Research, Vol. 12 No. 3, pp. 223-36.

Lockshin, L.S., Spawton, A.L. and Macintosh, G. (1997), "Using product, brand and purchasing involvement for retail segmentation”, Journal of Retailing and Consumer Services, Vol. 4 No. 3, pp. 171-83.

Lockshin, L.S., Macintosh, G. and Spawton, A. (1997), "A cross-cultural comparsion of retail segmentation using product and purchasing involvement", Fourth Recent Advances in Retailing and Services Science Conference, Scottsdale, AZ, pp. 46.

Marangon, F. and Troiano, S. (2004), "Caratteristiche dei consumatori e preferenze per i vini italiani di qualità. Il caso di Civintas", in Marangon, F., Moretti, A. and Zaccomer, G.P. (a cura di), Economia e management del vino, Giappichelli Editore, Torino.

Mittal, B. (1995), "A comparative analysis of four scales of consumer involvement", Psychology and Marketing, Vol. 12 No. 7, pp. 663-82.

Mittal, B. (1989), "Measuring purchase-decision involvement”, Psychology and Marketing, Vol. 16, pp. 147-162.

Mittal, M. and Lee, M. (1989), "A causal model of consumer involvement", Journal of Economic Psychology, Vol. 10, pp. 363-89. 
Punj, G. and Stewart, D.W. (1983), "Cluster analysis in marketing research: review and suggestions for application”, Journal of Marketing Research, Vol. 20, pp. 134-48.

Rothschild, M.L. (1984), "Perspectives on involvement: Current problems and future directions",

Wine consumer's behaviour in Kinnear, T. (Ed.), Advances in Consumer Research, Vol. 11, Association for Consumer Research, Ann Arbor, MI, pp. 216-217.

Sherif, M. and Cantril, H. (1947), The Psychology of Ego Involvement, Wiley, New York, NY.

Singh, J. (1990), "A typology of consumer response styles”, Journal of Retailing, Vol. 66 No. 1, pp. 57-99.

Slama, M. and Tashchian, A. (1985), "Selected socioeconomic and demographic characteristics associated with purchasing involvement", Journal of Marketing, Vol. 49 No. 1, pp. 72-82.

Spawton, T. (1991), "Marketing planning for the wine industry”, European Journal of Marketing, Vol. 24 No. 3, pp. 6-48.

Valette F.P. (1989), “Conceptualisation et mesure de l'implication”, Recherche et Application en Marketing, Vol. 1, pp. 57-78.

Zaichkowsky, J. (1985), "Measuring the involvement construct", Journal of Consumer Research, Vol. 12 No. 3, pp. 341-52.

\section{About the authors}

Chiara Seghieri is a researcher for the Department of Agricultural Economic and Land Resources at the University of Florence. She holds a $\mathrm{PhD}$ in Applied Statistics from the Department of Statistics, University of Florence. Her current research interests include quality of life studies, demand analysis, and consumer behaviour. Chiara Seghieri is the corresponding author and can be contacted at: c.seghieri@sssup.it

Leonardo Casini is deputy rector at the University of Florence and professor of Agricultural Economics.

Francesco Torrisi is an assistant professor in the Department of Agricultural Economic and Land Resources at University of Florence. He holds a PhD in Economics and Forest Management from the University of Florence. His current research interests include the wine market and consumer behaviour.

To purchase reprints of this article please e-mail: reprints@emeraldinsight.com Or visit our web site for further details: www.emeraldinsight.com/reprints 